\title{
A New Compound $(8,9)$-Furanyl-Pterocarpan-3-0l Used for Standardization of Bengkuang (Pachyrhizus erosus) Extract as Sunscreen and Skin Whitening Agent
}

\author{
Endang Lukitaningsih ${ }^{1, *}$, Ulrike Holzgrabe ${ }^{2}$ \\ ${ }^{1}$ Department of Pharmaceutical Chemistry, Faculty of Pharmacy, Universitas Gadjah Mada, Yogyakarta, Indonesia \\ ${ }^{2}$ Institut of Pharmacy, Wuerzburg University, Am Hubland, 97078, Wuerzburg, Germany
}

\begin{abstract}
Bengkuang (Pachyrhizus erosus) has been traditionally used as sun screening and skin whitening. The active compounds in bengkuang extract already published included their activities in antioxidant and skin whitening. However, standardization of bengkuang extract has not been studied. Therefore, current research was conducted to find out the analysis procedure by High Performance Liquid Chromatography to make standardization bengkuang extract. The first step of this research was collecting bengkuang from Prembun, Central Java, Indonesia in dry season. After cleaning and peeling, bengkuang root was sliced, dried and ground to make powder. Then followed by extraction using Soxhlet in petroleum ether and subsequently in methanol. Methanol extract was evaporated and then partitioned with ethyl acetate-water. Ethyl acetate fraction was evaporated and then separated in open column chromatography using silica gel as stationary phase and a gradient mixture of chloroform-ethyl acetate-methanol as mobile phase. Bio guided fraction method was used for separation and purification to get isolated compounds. The isolated compounds obtained from this fractionation were then elucidated and analyzed their activities.

A new compound (8,9-furanyl-pterocarpan-ol) has been selected as a biomarker for extract standardization. The optimum of HPLC condition for standardization consisted of a column (Zorbax SB-C18; i.d. $0.46 \mathrm{~cm}$; $5 \mu \mathrm{m}$ particle size), mobile phase (gradient elution of $\mathrm{MeOH}$-water) with flow rate of $1 \mathrm{~mL} / \mathrm{min}$ and detector (UV-detector at 293 $\mathrm{nm})$. The obtained LOD value was $0.51 \pm 0.02 \mu \mathrm{g}$. The potentials of this compound to absorb UV ray, antioxidant and anti-tyrosinase were $4.018 \mathrm{mAU} * \mathrm{~S} / \mathrm{mmL} ; 2.113 \pm 0.001 \mathrm{mM}$ $\left(\mathrm{SC}_{50}\right) ; 7.19 \pm 0.11 \mathrm{mM}\left(\mathrm{IC}_{50}\right)$, respectively.
\end{abstract}

Keywords : bengkuang (Pachyrhizus erosus) extract, (8,9)-furanyl-pterocarpan-3-ol, standardization, sunscreen, skin whitening

\section{INTRODUCTION}

Bengkuang (Pachyrhizus erosus) is a species of a Pachyrizus and grows naturally in Indone-
Submitted: April 23, 2019

Revised: May 18, 2019

Accepted: May 22, 2019

*Corresponding author: lukitaningsih_end@ugm.ac.id 
sia and many other tropical and subtropical countries. The root or tuber of bengkuang (Pachyrhizus erosus) is part of this tree that it is usually eaten raw, sometimes with powdered chili. In Indonesia, bengkuang roots have also been traditionally used as a cosmetic material for centuries ago based on ancestor's experience (Lukitaningsih and Holzgrabe, 2014). As a tropical country near the equator, exposure of ultraviolet (UV) ray occurred every day in high intensity. Therefore, a demand of cosmetics containing sunscreen and skin whitening is always high in Indonesia, primarily cosmetics that having natural sources as an active ingredient, such as containing bengkuang extract.

UV radiation is already known to cause most the visible signs of aging (Kim, et al., 2010; Menaa, et al., 2014), because it increases reactive oxygen species (ROS) in the body (Karim, et al., 2014) that disturbing the balancing of ROS and antioxidant level (Poljsâk, et al., 2012). The skin becomes coarse, wrinkles, xerosis or low humidity, as well as hyperpigmentation (Tobin, 2017). Therefore, exogen antioxidant is necessary to improve this balancing, such as vitamin $\mathrm{C}$, vitamin $\mathrm{E}$, and some natural sources which containing anthocyanin, phenolic or flavonoid compounds (Zhu, et al., 2015; Zhang, 2013; Giamperi, et al., 2014). Besides that, tysrosinase inhibitor compound is also needed to overcome hyperpigmentation, such as kojic acid, arbutin, and flavonoid compounds as well. (Ochiai, et al., 2016; El Zawawy and Ali, 2016).

Some of compounds in bengkuang roots have already known and reported their activities as sunscreen, antioxidant and anti-tyrosinase. Lukitaningsih, et al. (2013) reported four compounds isolated from bengkuang (Pachyrhizus erosus), three of them belong to isoflavonoid, namely daidzein, daidzein-7-O-ß-glucopyranose and 5-hydroxy-daidzein-7-O-ß-glucopyranose. One other compound is pterocarpon group, namely 8,9 -furanyl-pterocarpan-3-ol. All of these compounds isolated from the ethyl acetate fraction. In addition, bengkuang has micronutrient compounds that essential for skin care, i.e. vitamin C, vitamin A and alpha hydroxy acid (Widyatmoko, et al., 2016). Vitamin C is important for antioxidant, regeneration skin cell and also as promoting collagen synthesis (Boyera, et al., 1998; D'Anielo, et al,, 2017). Vitamin A can be used to treat acne, has an important role to reduce collagen breakdown, induce type I and type III procollagen gene expression resulting collagen fibrils in the dermis (Manela-Azulay and Bagatin, 2009). In addition, alpha hydroxy acid is needed for peeling dead skin cells in the stratum corneum and antiaging (Tran, et al., 2014). Therefore, it is possible that bengkuang used traditionally as skin whitening or skin care for many years ago. Bengkuang root not only has an important role in skin whitening treatment, but also can be used as an osteoporosis prevention agent. Ethyl acetate extract of bengkuang root can inhibit bone loss in an ovariectomized rat model. The compounds in bengkuang may offer a potential therapy for post-menopausal women (Nurrochmad, et al., 2010).

Extract of natural product that used as active material in pharmaceutics, food or cosmetics products should be safe and comply with quality control regulation trough standardization procedure. Standardization is a step to give confirmation of identity, quality and purity of the drug or extract (Pandey and Tripathi, 2014). Standardization of extract using active compound can provide more benefit value not only for qualification in physical and chemical properties or biomarker analysis, but also giving efficacy or clinical confirmation. Standardization bengkuang extract using bioactive has not reported yet. This research aims to study how to isolate and analysis 8,9-furanyl-pterocarpan-3-ol as a biomarker of bengkuang extract.

\section{METHODS}

\section{Chemicals and Solvent}

Bengkuang was obtained from Prembun, Central Java, Indonesia in dry season. Petroleum ether, ethyl acetate (Fisher Scientific, Leichestershire, UK), methanol (Merck, Darmstadt, Germany), and chloroform (Fluka, Seelze, 
Germany) were used for solvent in extraction. Silica gel 60 (particle sizes 0.063-0.200mm, Merck, Darmstadt, Germany), TLC Aluminium sheets, silica gel 60 F254 (layer thickness $0.2 \mathrm{~mm}$, Merck, Darmstadt, Germany) were used for separation and purification of bengkuang extract. The chemicals used in the detection and isolation methods were mushroom tyrosinase $4187 \mathrm{IU} / \mathrm{mg}$, L-DOPA (dihydroxy phenyl alanine), kojic acid (Fluka, Seelze, Germany), dimethylsulfoxide (DMSO) extra pure (Acros ${ }^{\circledR}$ organic, Geel, Belgium), DPPH (1,1-diphenyl-1-picrylhydrazine), Dulbeco's phosphate buffered saline, (purchased from Sigma Aldrich, Steinheim Germany), ascorbic acid (Sigma Aldrich, Steinheim, Germany).

\section{Instruments and General Methods}

Cary 50 Bio UV-Visible spectrophotometer (Varian, California, USA), JASCO FT/IR-6100 Spectrometer (Gross-Umstadt, Germany), Thermo Mixer Comfort 5355 V.2.12 Eppendorf (Hamburg, Germany), ALPHA II-12 Freeze dryer (Osterode, Germany), Bruker Avance 400 NMR spectrophotometer (Rheinstetten, Germany), Agilent 1100 series High Performance Liquid Chromatography (HPLC) apparatus (California, USA) equipped by column Zorbax SB-C18 $(25 \mathrm{~cm}$, i.d. $0.46 \mathrm{~cm}, 5 \mu \mathrm{m}$, Agilent, California, USA), UV absorbance detector and Electro Spray Ionization-Mass Spectrophotometer (ESI-MS) detectors, Agilent 1100 series preparative-HPLC (California, USA) equipped by

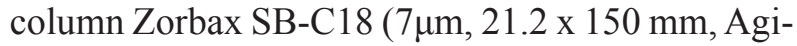
lent, California, USA).

\section{Plant Material and Extraction}

The bengkuang roots in the amount of 45 $\mathrm{kg}$ were peeled, washed, and subsequently dried at $60^{\circ} \mathrm{C}$ and milled into fine powder. The fine powder $(4.75 \mathrm{~kg})$ was extracted by Soxhlet using $6 \mathrm{~L}$ petroleum ether. The residue was extracted using methanol to achieve the semi polar and polar compounds. The extracts were filtered and concentrated in vacuo. The concentrated methanol extract was then partitioned with ethyl acetate-water. The ethyl acetate phase was further collected and concentrated (Lukitaningsih and Holzgrabe, 2014).

Compound Isolation of Ethyl Acetate Extract

The ethyl acetate extract (31.1 gram) was subjected to silica gel column chromatography and eluted using the gradient mixture of petroleum ether-ethyl acetate and ethyl acetate-methanol producing 35 fractions of $100 \mathrm{~mL}$ eluents. All fractions were detected in thin layer chromatography (TLC) using silica gel as stationary phase and mixture of petroleum ether-ethyl acetate (6:4) as a mobile phase. Fractions 12-24 which have an Rf value of 0.17 (positive with DPPH) were collected and evaporated. The fractions may contain antioxidant compounds because the spot was able to reduce DPPH (Lukitaningsih and Holzgrabe, 2014). The concentrated fraction was then purified using preparative HPLC using a gradient concentration of $\mathrm{MeOH}$-water as a mobile phase. The operating system of semipreparative HPLC consists of Zorbax SB-C18 (150 mm; i.d. $21.2 \mathrm{~mm}$; $7 \mu \mathrm{m}$ particle size), mobile phase in gradient elution mode (concentration of methanol was adjusted $20 \%$ at $0-2$ min, then increased until $100 \%$ at $20 \mathrm{~min}$ and finally maintained constant $100 \%$ for $5 \mathrm{~min}$ ), flow rate of $10 \mathrm{~mL} / \mathrm{min}$ and detected under $254 \mathrm{~nm}$. Approximately 670 mg yellow crystal (A182) was obtained and identified as $(8,9)$-furanyl-pterocarpan-3-ol.

\section{Validation Method of $(8,9)$-pterocarpan-3-ol Analysis using HPLC}

$10.0 \mu 1$ of $0.1 \mathrm{mg} / \mathrm{mL}(8,9)$-furanyl-pterocarpan-3-ol solution in methanol was injected into HPLC using stationary phase Sorbax C-18 (150 $\mathrm{mm}$; i.d. $4.6 \mathrm{~mm} ; 5 \mu \mathrm{m}$ particle size) and elution programs as in semipreparative HPLC, flow rate of $1 \mathrm{~mL} / \mathrm{min}$. A concentration series of $(8,9)$-furanyl-pterocarpan-3-ol solution was formed by range concentrations of $0.1 ; 0.2 ; 0.6 ; 3.0 ; 5.0 \mu \mathrm{g} / \mathrm{mL}$ in methanol. Each solution was injected into the HPLC which has been optimized with injection volume of $20 \mu \mathrm{L}$. The analysis was carried out in triplicate. The obtained data were used to determine parameters of linearity, sensitivity and repeatability. 


\section{Antioxidant Activity Assay}

The antioxidant activity was determined by measuring the scavenging activity assay against DPPH radical according to Gülçin (2012). The amount of $4 \mathrm{~mL}$ of 1,1-diphenyl-2-picrylhydrazyl (DPPH) solution $100 \mu \mathrm{M}$ in methanol was thoroughly mixed with $1 \mathrm{~mL}$ of a sample solution at various concentrations. The mixture was kept in the dark for 30 minutes. The absorbance of these solutions was measured at $517 \mathrm{~nm}$. Ascorbic acid was used as a positive control $\left(\mathrm{IC}_{50} 7.24 \mathrm{ppm}\right)$, while $5 \mathrm{~mL}$ DPPH radical solution with concentration of $100 \mu \mathrm{M}$ in methanol was used as initial solution. The concentration in ppm at which the absorbance decreases to $50 \%$ of its initial value was used as the $\mathrm{SC}_{50}$ value for each test solution. All tests were done in triplicate.

\section{Tyrosinase Inhibition Assay}

Tyrosinase inhibitory activity was measured according to Hearing (1987) and Rangkadilok, et al., (2006) with a slight modification as in Lukitaningsih and Holzgrabe (2014) using mushroom tyrosinase as the enzyme, L-DOPA as a substrate and kojic acid as a positive control. An aliquot $(50 \mu \mathrm{l})$ of samples in DMSO was mixed with $100 \mu$ l of $200 \mathrm{IU} /$ $\mathrm{mL}$ of mushroom tyrosinase and $100 \mu$ of phosphate buffered saline $(\mathrm{pH}$ 6.8). The assay mixture was pre-incubated at $37^{\circ} \mathrm{C}$ for $10 \mathrm{~min}$ and then $100 \mu \mathrm{l}$ of

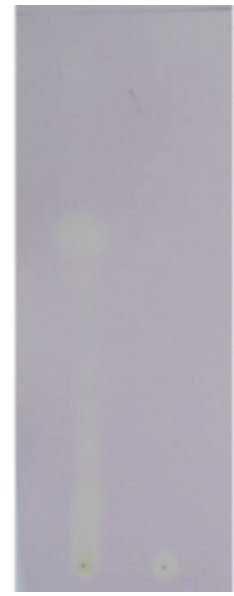

EE-1 ME-1

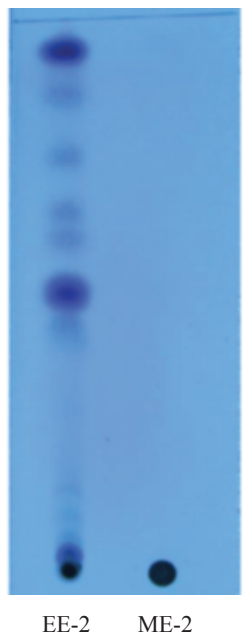

EE-2 ME-2

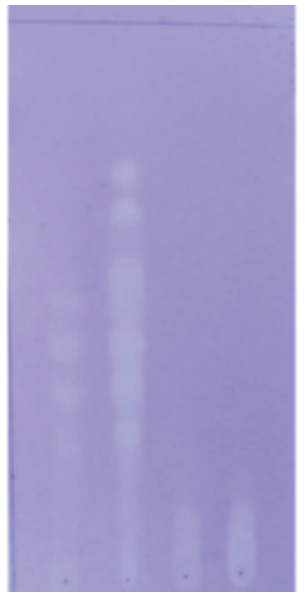

F1-1 F2-1 F3-1 F4-1

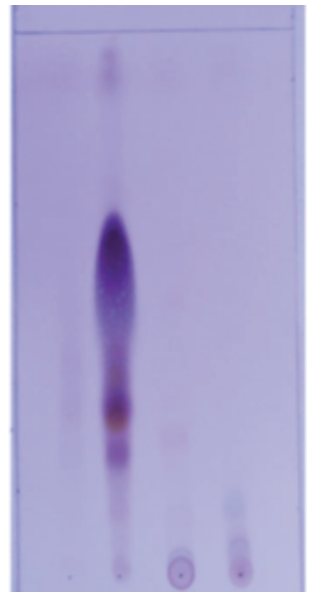

F1-2 F2-2 F3-2 F4-2
L-1,4-dihydroxyphenylalanine (L-DOPA) solution $7.6 \mathrm{mM}$ was added. This reaction mixture incubated for $15 \mathrm{~min}$ at $37^{\circ} \mathrm{C}$. The dopachrome was measured at $475 \mathrm{~nm}$ using a UV/Vis spectrophotometer (A). As a blank, DMSO was used (B). As a color control test, phosphate buffer was used instead of the enzyme tyrosinase (C). The percentage of tyrosinase inhibitions were expressed as a percentage of inhibition of tyrosinase activity and calculated as follows: Tyrosinase inhibition (\%) $=\{\mathrm{B}-(\mathrm{A}-\mathrm{C})\} / \mathrm{B}$ X $100 \%$ Kojic acid was used as a standard inhibitor for tyrosinase. All tests were done in triplicate.

\section{Determination of Tyrosinase Inhibition Type}

Determination of the tyrosinase inhibition type of isolated compounds was carried out according to Chen and Kubo (2002) and Lukitaningsih, et al., (2013) with a little modification. The principle reaction was a kinetic reaction between compound A182 in series concentration and DOPA in fix concentration under tyrosinase enzyme activity.

\section{RESULTS}

\section{Compound Isolation}

Ethyl acetate extract of bengkuang has been analyzed by TLC and HPLC to find out how many compounds in each extract and their distribution and the result was presented in Figure 1.

Figure 1. TLC Result of Ethyl Acetate Extract (EE), Methanol Extract (ME) and Fractions of Ethyl Acetate Extract that analyzed on Silica gel TLC using a mobile phase of Petroleum ether-Ethyl acetate (6:4) and detected with DPPH radical spray (1) and anisaldehyde-H2SO4 spray followed by heating. 
Based on the result in Figure 1, it can be seen that the ethyl acetate extract (EE-1) contains many compounds that having antioxidant activity, because it can reduce DPPH radical and change the colour of spots from violet to yellow. The TLC profile of ethyl acetate extract detected using radical DPPH spray (EE-1) was different from the profile detected using anisaldehyde- $\mathrm{H}_{2} \mathrm{SO}_{4}$ (EE-2). The same result appeared also in profile of fraction F14. It showed that not all compounds found in EE-2 have antioxidant activity. Fraction F2 was chosen for further analysis, because it contained many antioxidant compounds.

Separation and purification of F2 were not sufficient conducted by TLC, because many spots appeared on the TLC. Therefore, it was necessary a high separation method. In this research, preparative HPLC equipped with C18 column and mobile phase of the mixture methanol-water in gradient elution mode under detected UV-detection was used and giving a good separation as presented in Figure 2.

The obtained compound which having Rf of 18.22 min was A182 and identified as $(8,9)$-furanyl-pterocarpan-3-ol (Lukitaningsih and Holzgrabe, 2014). It has high activity to absorb UV ray at the maximum wavelength of $293 \mathrm{~nm}$ with absorptivity molar value $(\varepsilon)$ of 11.690 in methanol. The UV spectrum of the compound can be found in Figure 3.

\section{New Compound A182 (8,9-Furanyl-ptero- carpan-3-ol)}

New compound A182 has identified and reported in Lukitaningsih and Holzgrabe (2014). New compound A182 was as yellow crystal; can absorb UV with $\lambda_{\max }$ of $293 \mathrm{~nm}$ in $\mathrm{MeOH}$; MW 280; IR $\left(\mathrm{cm}^{-1}\right)$ : 3295, 1624, 1607 , $1540,1494,1469,1353,1306,1270,1229$, 1144, 1123, 1055, 1018, 960, 843, 826, 764; ESI-MS m/z (\% intensity): $281.3\left([\mathrm{M}+\mathrm{H}]^{+}\right.$, $100), 123.1\left(\left[\mathrm{C}_{7} \mathrm{H}_{7} \mathrm{O}_{2}\right]^{+}, 100\right), 121.0\left(\left[\mathrm{C}_{7} \mathrm{H}_{7} \mathrm{O}_{2}\right]^{-}\right.$, 100); ${ }^{1} \mathrm{H}$ NMR (500 MHz, MeOH-d ${ }_{4}$ ): 3.44 (dd, $\left.1 \mathrm{H}, \mathrm{H}^{6 \mathrm{a}}\right), 3.48\left(\mathrm{~d}, 1 \mathrm{H}, \mathrm{H}^{6}\right), 4,14\left(\mathrm{~d}, 1 \mathrm{H}, \mathrm{H}^{6}\right)$, $5.49\left(\mathrm{~d}, 1 \mathrm{H}, \mathrm{H}^{11 \mathrm{a}}\right), 6.17\left(\mathrm{~d}, 1 \mathrm{H}, \mathrm{H}^{4}\right), 6.22(\mathrm{dd}$, $\left.1 \mathrm{H}, \mathrm{H}^{2}\right), 6.66\left(\mathrm{~d}, 1 \mathrm{H}, \mathrm{H}^{3}\right), 6.89\left(\mathrm{~s}, 1 \mathrm{H}, \mathrm{H}^{10}\right)$, $6.95\left(\mathrm{~d}, 1 \mathrm{H}, \mathrm{H}^{1}\right), 7.53\left(\mathrm{~d}, 1 \mathrm{H}, \mathrm{H}^{2}\right), 7.57(\mathrm{~s}, 1 \mathrm{H}$, $\left.\mathrm{H}^{7}\right) ;{ }^{13} \mathrm{C}$ NMR $\left(125 \mathrm{MHz}, \mathrm{MeOH}-\mathrm{d}_{4}\right): 124.66$ $\left(\mathrm{C}^{1}\right), 107.40\left(\mathrm{C}^{2}\right), 160.53\left(\mathrm{C}^{3}\right), 97.35\left(\mathrm{C}^{4}\right)$, $158.45\left(\mathrm{C}^{4 \mathrm{a}}\right), 66.84\left(\mathrm{C}^{6}\right), 39.73\left(\mathrm{C}^{6 \mathrm{a}}\right), 116.90$ $\left(\mathrm{C}^{6 \mathrm{~b}}\right), 122.89\left(\mathrm{C}^{7}\right), 122.19\left(\mathrm{C}^{8}\right), 155.61\left(\mathrm{C}^{9}\right)$, $98.87\left(\mathrm{C}^{10}\right), 153.61\left(\mathrm{C}^{10 \mathrm{a}}\right), 79.02\left(\mathrm{C}^{11 \mathrm{a}}\right), 118.03$ $\left(\mathrm{C}^{11 \mathrm{~b}}\right), 145.07\left(\mathrm{C}^{2}\right), 105\left(\mathrm{C}^{3^{\prime}}\right)$

\section{Validation Method of $(8,9)$-furanyl-pterocar- pan-3-ol Analysis Using HPLC}

The compound A182 collected from semipreparative HPLC was then analyzed by analytical HPLC using system as in method. The result can be seen in Figure 4.

Based on Figure 4, it was known that the purity of A182 was about $91.29 \%$ calculated under normalized of area under the peak. The linearity, sensitivity and repeatability parameters have also been determined using the optimum HPLC system. These parameters can be found in Table I.

\section{Antioxidant Activity Assay}

The antioxidant activity of the compound A182 was evaluated by means of scavenging activity assay using DPPH radical and ascorbic acid as a positive control. The correlation of the scavenging free radical of isolated compounds was displayed in Figure 5. From this correlation in Figure 5, $\mathrm{SC}_{50}$ of compound A182 can be calculated and the result was $2.11 \pm 0.001 \mu \mathrm{g} / \mathrm{mL}$ or $8.79 \mu \mathrm{M}$, while $\mathrm{SC}_{50}$ value of vitamin $\mathrm{C}$ as a positive standard was $7.24 \pm 0.05$ $\mu \mathrm{g} / \mathrm{mL}$ or $40 \mu \mathrm{M}$.

\section{Tyrosinase Inhibition Assay}

The result of tyrosinase inhibition of compound A182 was presented in Figure 6, while Figure 7 displayed the Lineweaver-Burk plot to determine the type of inhibition. 
Indonesian Journal of Cancer Chemoprevention, June 2019

ISSN: 2088-0197

e-ISSN: 2355-8989
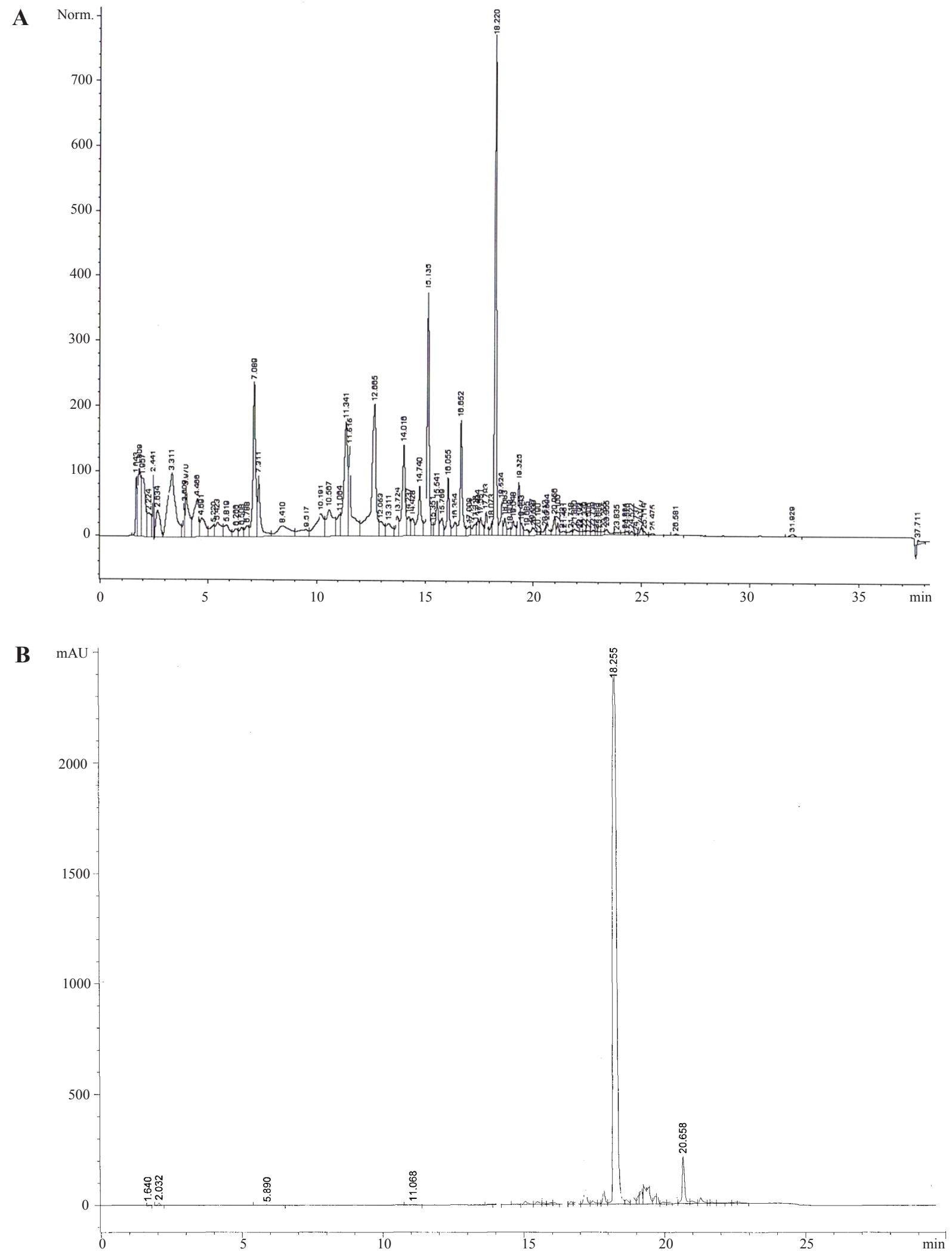

Figure 2. Chromatograms of Fraction F3 analyzed using semipreparative HPLC (A) and isolate A182 determined after purification by semipreparative HPLC (B). 


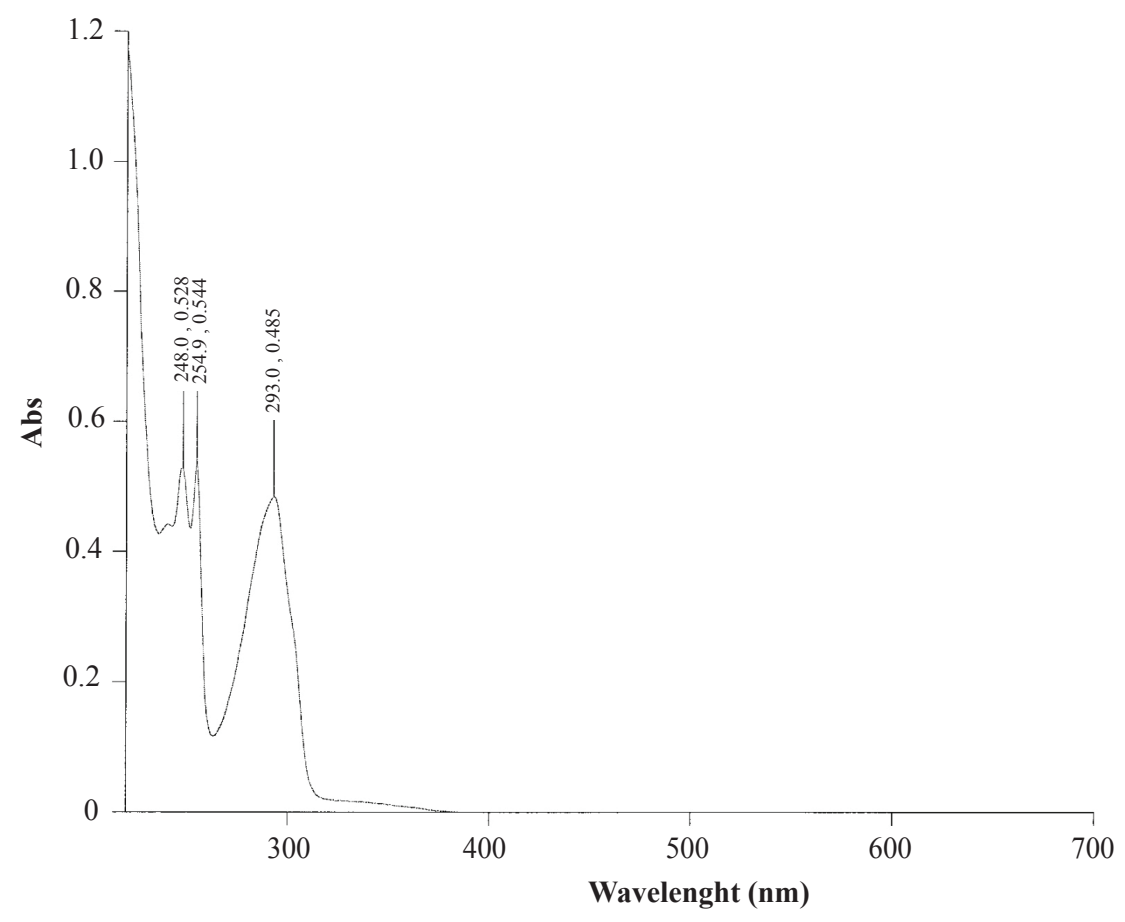

Figure 3. UV spectrum of compound (8,9)-furanyl-pterocarpan-3-ol ( $\lambda$ max $293 \mathrm{~nm}$, measured in methanol).

\section{DISCUSSION}

TLC chromatogram (Figure 1) showed that ethyl acetate extract was containing more kinds of active compounds (antioxidant compounds) rather than in methanol extract, because it appeared many spots under DPPH spray detection. In addition, many compounds in ethyl acetate extract probably belongs to terpenoid, since it showed positive reaction under anisaldehyde- $\mathrm{H}_{2} \mathrm{SO}_{4}$ spray continued with heating. In the deep determination, it was known that stigmasterol and $\beta$-sitosterol were the most terpenoid found in ethyl acetate extract (Lukitaningsih and Holzgrabe, 2014). After the fractionation process of ethyl acetate extract, it was known that F3 (mixture of fraction 12-24) was the most potent extract, therefore $\mathrm{F} 3$ was chosen for the next isolation. TLC wasn't giving a sufficient separation. Therefore, preparative HPLC was used to get a purify isolated compound. Based on Figure 2, a compound with retention time of $18.255 \mathrm{~min}$ had the highest intensity, so that it was chosen as a biomarker for standardization. In the future determination, this compound was identified as A182 or $(8,9)$-furanyl-pterocarpan-3-ol. The purity of A182 compound was $91.29 \%$ (normalized area). This substance was an interesting compound because of its ability to absorb UV ray, antioxidant and anti-tyrosinase activity as well. The compound A182 had high activity to absorb UV light at the maximum wavelength of $293 \mathrm{~nm}$ with absorptivity molar value $(\varepsilon)$ of 11.690 in methanol. Validation method for quantification of compound A182 by using HPLC showed that the results met with the acceptance criteria for linearity $\left(\mathrm{R}^{2}\right.$ more than 0.99), repeatability (within 95-105\%) and also the sensitivity parameter that can be applied in low concentration (in $0.5 \mu \mathrm{g} / \mathrm{mL}$ ) (Chan, et al, , 2004).

Antioxidant activity of compound A182 has been determined by spectrophotometer using DPPH radical. The parameter for interpretation of the results was the "scavenging free radical concen- 


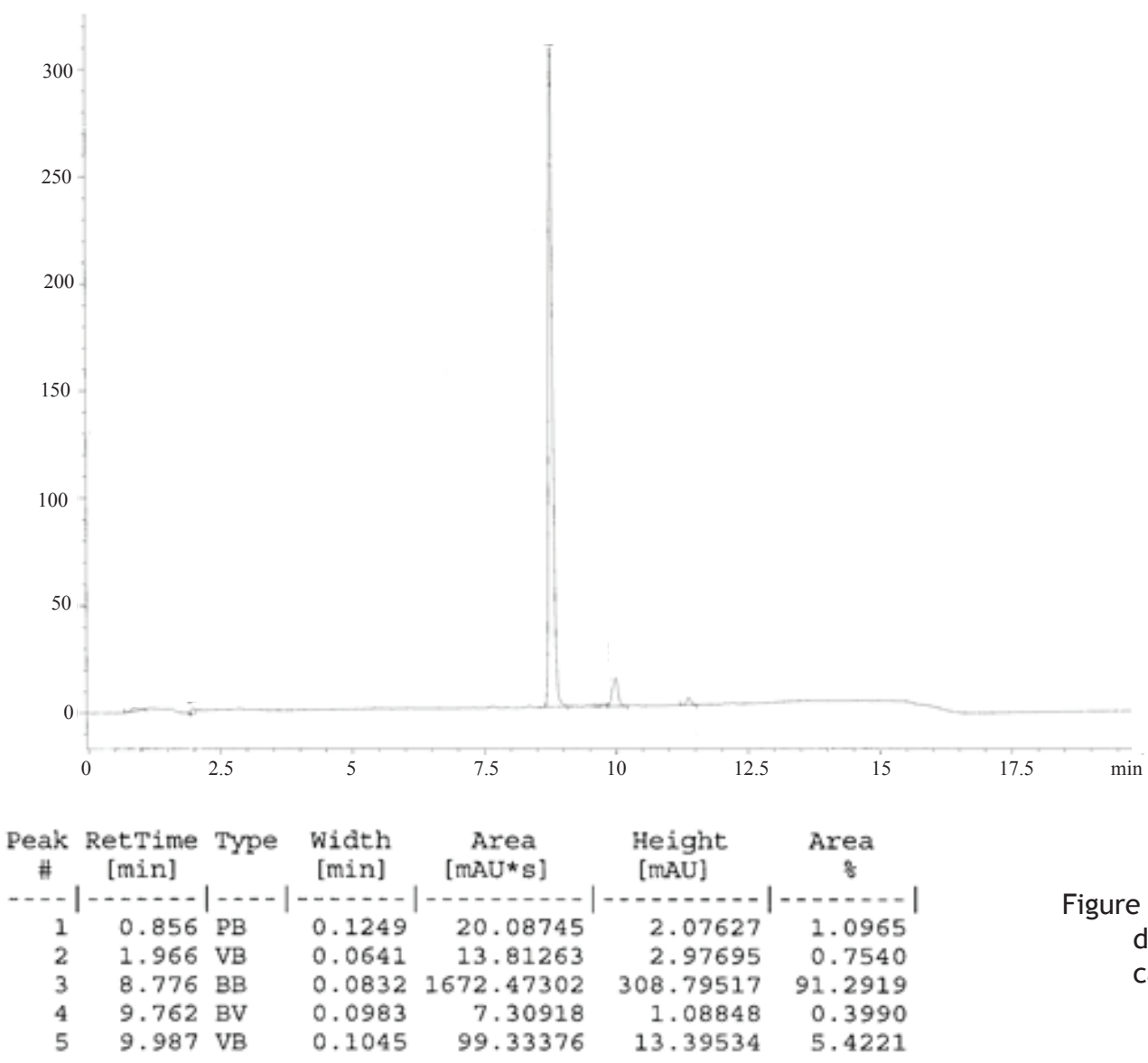

Figure 4. Chromatogram of A182 determined using analytical HPLC.

tration" or $\mathrm{SC}_{50}$ value that defined as the concentration of substance that causes $50 \%$ loss of the DPPH activity (colour), i.e. the higher the antioxidative activity, the lower was the value of $\mathrm{SC}_{50}$. To compare the antioxidant potential in DPPH method, it should be considered the molecular weight or the structure of the substrate, since the reaction between DPPH radical and active compound depends on the stoichiometry (Kedare and Singh, 2011). The antioxidant potential of A182 $\left(\mathrm{SC}_{50}=2.11 \pm 0.001 \mu \mathrm{g} / \mathrm{mL}\right.$ or $8.79 \mu \mathrm{M}$ ) was about five times much better than vitamin $\mathrm{C}\left(\mathrm{SC}_{50}=7.24 \pm 0.05 \mu \mathrm{g} / \mathrm{mL}\right.$ or $\left.40 \mu \mathrm{M}\right)$.

Table I. Linearity, sensitivity and repeatability parameters of HPLC system.

\begin{tabular}{lcc}
\multicolumn{1}{c}{ Linearity } & Sensitivity & Repeatability \\
\hline Linear regression: & Limit of detection: & Repeatability: \\
$\mathbf{Y}=\mathbf{1 1 2 5 . 1} \mathbf{X}+\mathbf{3 3 7 . 6}$ & $(0.51 \pm 0.02) \mu \mathrm{g} / \mathrm{mL}$ & $(98.98 \pm 0.07) \%$ \\
$\mathrm{Y}:$ Area $(\mathrm{mAU} * \mathrm{~S})$ & & \\
$\mathrm{X}:$ concentration $(\mu \mathrm{g} / \mathrm{mL})$ & Limit of determination: & \\
$\mathrm{R}^{2}: 0.9949$ & $(1.72 \pm 0.05) \mu \mathrm{g} / \mathrm{mL}$ & \\
Range linear: $1.0-100.0 \mu \mathrm{g} / \mathrm{mL}$ & & \\
\hline
\end{tabular}

Note: the data presented in this table were calculated from triplicate measurements. 


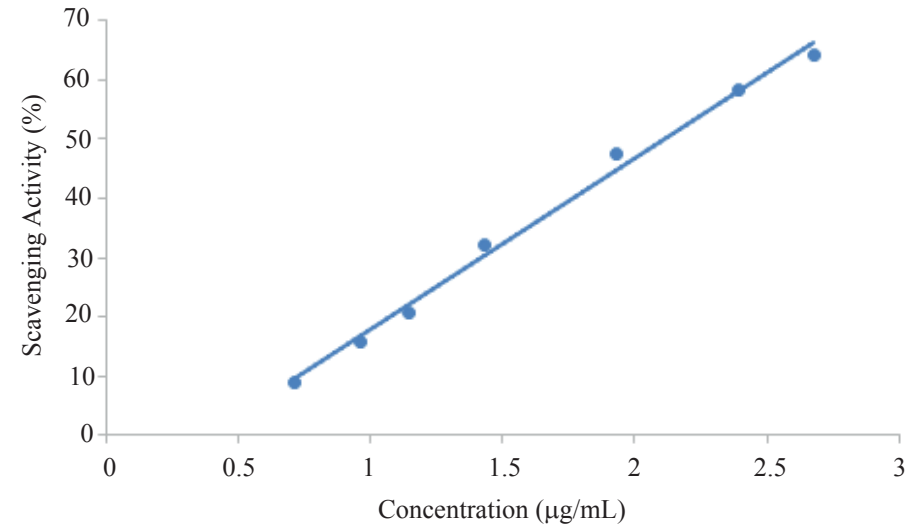

Figure 5. The correlation of scavenging DPPH radical activity of compound $\mathrm{A} 182$ against concentration (from three replicate analysis). The $X$ axis was concentration of coumpound $\mathrm{A} 182(\mu \mathrm{g} / \mathrm{ml})$ and the $Y$ axis was percentage of scavenging activity.
Inhibitory activity of compound A182 against tyrosinase has been also measured by in vitro. The catalytic action of tyrosinase enzyme was the conversion of tyrosine with oxygen to give DOPA, which was then converted to dopaquinone and water. Subsequently, dopaquinone was converted through autooxidation to dopachrome, an orange to red pigment with an absorbance maximum at 475 $\mathrm{nm}$. Tyrosinase inhibition is an important role to reduce hyperpigmentation on the skin, both caused by extra exposure of UV ray and other factors. The result of tyrosinase inhibition showed a significant correlation between the concentration of compound $\mathrm{A} 182$ and the tyrosinase inhibitory activity. The $\mathrm{IC}_{50}$ value of the compound $\mathrm{A} 182$ and kojic acid were $1.21 \pm 0.02 \mu \mathrm{g} / \mathrm{mL}$ (or $5.04 \mathrm{mM}$ ) and $0.070 \pm 0.001$ $\mu \mathrm{g} / \mathrm{mL}$ (or $0.49 \mathrm{mM}$ ), respectively. From this result, it showed that the potency of A182 was 10\% lower than the potency of kojic acid. The compound A182 belonged to a non-competitive inhibitor based on the Lineweaver-Burk plots profile (Figure 7), since it might be due to its ability to bind with tyrosinase not at an active site of the enzyme (at allosteric site). Related to quality control of bengkuang extract, the isolated compound A182 can be developed as biomarker, not only to control the chemical properties, but also to control the efficacy of bengkuang extract in term of antioxidant, sunscreen, as well as anti-tyrosinase activity. The RP-HPLC method developed in this research can be applied for routine standardization bengkuang extract, because of its sensitivity, repeatability, rapid and simple.

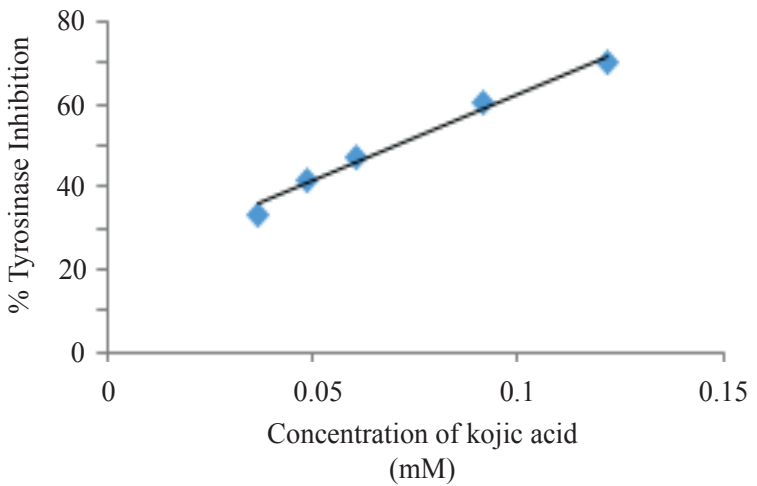

Figure 6. Tyrosinase inhibitory activity of A182 and kojic acid as a positive standard. The $X$ axis was concentration of coumpound $(\mathrm{mM})$ and the $Y$ axis was percentage of tyrosinase inhibition. 


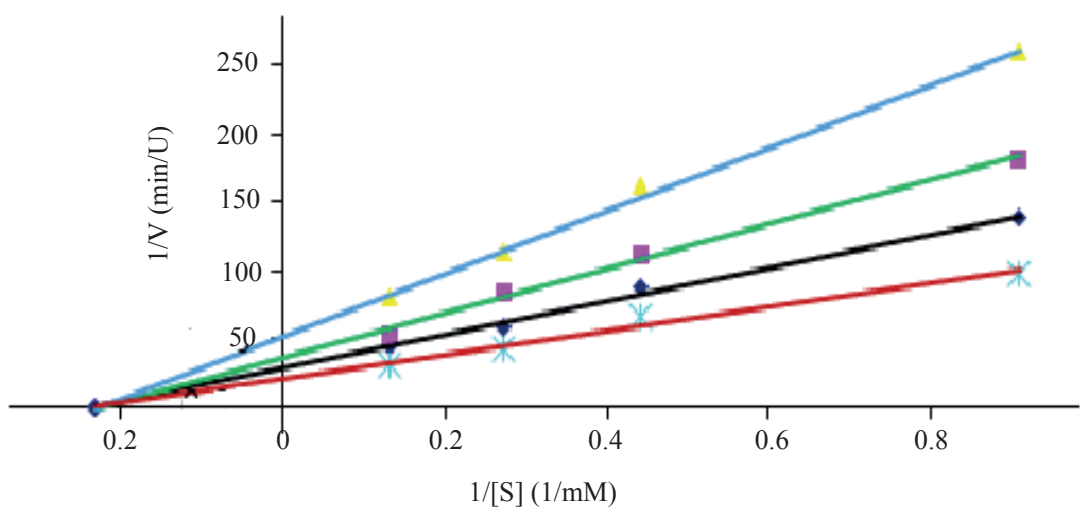

- Comp A182 (1,775 mM)

Comp A182 (1,596 mM)

Figure 7. Lineweaver-Burk plot of A182 on mushroom tyrosinase for the DOPA catalysis. The X axis was $1 /$ [reaction rate constant] and the $Y$ axis was $1 /$ [concentration of DOPA as substrate].

\section{CONCLUSION}

A new compound (8,9-furanyl-pterocarpan-ol) isolated from the ethyl acetate extract of bengkuang can be used as a biomarker for bengkuang extract standardization, because of its sensitivity and activities to absorb UV ray, antioxidant and anti-tyrosinase. The potentials of this compound to absorb UV ray, antioxidant and anti-tyrosinase are $4.018 \mathrm{mAU} * \mathrm{~S} / \mathrm{mL} ; 2.113 \pm 0.001 \mathrm{mM}$ $\left(\mathrm{SC}_{50}\right) ; 5.04 \pm 0.11 \mathrm{mM}\left(\mathrm{IC}_{50}\right)$, respectively. The obtained LOD and LOQ value are $0.51 \pm 0.02 \mu \mathrm{g} / \mathrm{mL}$ and $1.72 \pm 0.05 \mu \mathrm{g} / \mathrm{mL}$, respectively.

\section{ACKNOWLEDGMENTS}

We are grateful to the German Academic Exchange Service (DAAD) and Faculty of Pharmacy Gadjah Mada University for financial support.

\section{REFERENCES}

Boyera, N., Galey, I. and Bernard, B.A., 1998, Effect of vitamin $C$ and its derivatives on collagen synthesis and cross-linking by normal human fibroblast, Int. J. Cosmet. Sci., 20(3), 151-158

Chan, C.C., Lam, H., Lee, Y.C. and Zang, X.M., 2004, Analytical Method Validation and Instrument
Performance Verification, John Wiley \& Sons Inc., Canada, 16-24.

Chen, Q. and Kubo, I., 2002, Kinetics of mushroom tyrosinase inhibition by quercetin, J. Agric. Food Chem., 50, 4108-4112

D'Aniello, C., Cermola, F., Patriarca, E.J. and Minchiotti, G., 2017, Vitamin C in Stem Cell Biology: Impact on Extracellular Matrix Homeostasis and Epigenetics, Stem Cells Internat., 2017, Hindawi, 1-16

El-Zawawy, N.A. and Ali, S.S., 2016, Pyocyanin as anti-tyrosinase and anti tinea corporis: A novel treatment study, Microb. Pathogen., 100, 213220.

Giampieri, F., Alvarez-Suarez, J., Mazzoni, L., Forbes-Hernandez, T., Gasparrini, M., GonzàlezParamàs, A., et al., 2014, Polyphenol-Rich Strawberry Extract Protects Human Dermal Fibroblasts against Hydrogen Peroxide Oxidative Damage and Improves Mitochondrial Functionality, Molecules, 19, 7798-7816.

Gülçin, I., 2012, Antioxidant activity of food constituents: an overview, Archiv. Toxicol., 86, 345-391.

Hearing, V.J.Jr., 1987, In: Methods in Enzymology, Academic Press, New York, 142, 154-165

Tobin, D.J., 2017, Introduction to skin aging, J. Tissue Viability, 26(1), 37-46

Karim, A.A., Azlan, A., Ismail, A., Hashim, P., Gani, S. salwa abd, Zainudin, B.H., et al., 2014. Phenolic composition, antioxidant, anti-wrinkles and tyrosinase inhibitory activities of cocoa pod 
extract, BMC Complement. Alternat. Med., 14, 381.

Kedare, S.B. and Singh, R.P., 2011, Genesis and development of DPPH method of antioxidant assay, J. Food Sci. Technol., 48, 412- 422.

Kim, Y.H., Kim, K.H., Han, C.S., Yang, H.C., Park, S.H., Jang, H.-I., et al., 2010, Anti-wrinkle activity of Platycarya strobilacea extract and its application as a cosmeceutical ingredient, J. Cosm. Sci., 61, 211.

Lukitaningsih, E., Bahi, M. and Holzgrabe, U., 2013, Tyrosinase Inhibition Type of Isolated Compounds Obtained from Pachyrhizus erosus, Aceh Int. J. Sci. Technol., 2(3), 98-102

Lukitaningsih, E. and Holzgrabe, U., 2014, Bioactive Compounds in Bengkuang (Pachyrhizus erosus) as Antioxidant and Tyrosinase Inhibition Agents, Indonesian J. Pharm., 25(2), 68-75.

Manela-Azulay, M. and Bagatin, E., 2009, Cosmeceuticals vitamins, Clin. Dermatol, 27, 469-474

Menaa, F., Menaa, A. and Tréton, J., 2014, Polyphenols against Skin Aging in: Polyphenols in Human Health and Disease, Elsevier, 819-830.

Nurrochmad, A., Leviana F., Wulancarsari, C.G. and Lukitaningsih, E., 2010, Phytoestrogens of Pachyrhizus erosus prevent Bone Loss in an Ovariectomized Rat Model of Osteoporosis, Int. J. Phytomed, 2, 363-372.

Nurrochmad, A., Lukitaningsih, E., Monikawati, A., Septhea, D.B. and Meiyanto., E., 2013, Combination of low-concentration of novel phytoestrogen (8,9)-furanyl-pterocarpan-3-ol from Pachyrhizus erosus attenuated tamoxifen-associated growth inhibition on breast cancer T47D cells, Asian Pac. J. Trop. Biomed., 3(11), 847852.

Ochiai, A., Tanaka, S., Tanaka, T. and Taniguchi, M.,
2016, Rice Bran Protein as a Potent Source of Antimelanogenic Peptides with Tyrosinase Inhibitory Activity, J. Nat. Prod., 79, 2545-2551.

Pandey, P. and Tripathi, S., 2014, Concept of standardization, extraction and pre phytochemical screening strategies for herbal drug, J. Pharmacog. Phytocem., 2(5), 115-119.

Poljšak, B., Dahmane, R.G. and Godić, A., 2012, Intrinsic skin aging: the role of oxidative stress, Acta Dermatovenerol Alp Pannonica Adriat, 21, 33-36.

Rangkadilok, N., Sitthimonchai, S., Worasuttayangkurn, L., Mahidol, C., Ruchirawat, M. and Satayavivad, J., 2006, Evaluation of free radical scavenging and antityrosinase activities of standardized longan fruit extract, Food Chem. Toxicol., 1016-1024.

Sharma, O.P. and Bhat, J.K., 2009, DPPH antioxidant assay revisited, Food. Chem., 113(4), 12021205.

Tran, D., Townley, J.P., Barnes, T.B. and Greive, K.A., 2015, An antiaging skin care system containing alpha hydroxy acids and vitamins improves the biomechanical parameters of facial skin, Clin. Cosm. Invest. Dermatol, 8, 9-17.

Widyatmoko, A., Hastutik, D., Sudarmanto, A. and Lukitaningsih, E., 2016, Vitamin C, Vitamin A and Alpha Hydroxy Acid in Bengoang (Pachyrhizus erosus), Trad. Med. J., 21(1), 48-54.

Zhang, J., 2013, Antioxidants and Aging, in: Bioactive Food as Dietary Interventions for the Aging Population, Elsevier, 241-248.

Zhu, Q., Nakagawa, T., Kishikawa, A., Ohnuki, K. and Shimizu, K., 2015, In vitro bioactivities and phytochemical profile of various parts of the strawberry (Fragaria $\times$ ananassa var. Amaou), J. Function. Foods, 13, 38-49. 